\title{
Las visiones estratégicas de los emprendedores aplicadas en el Business Model Social: propuesta de una tipología
}

\section{Mónica Liliana Ramírez Álvarez*}

Fecha de recibido: 9 de febrero de 2018 Fecha de aprobado: 4 de abril de 2018

Para citar: Ramírez Álvarez, M. L. (2019). Las visiones estratégicas de los emprendedores aplicadas en el Business Model Social: propuesta de una tipología.

Universidad \& Empresa, 21(36), 196-227.

DOI: http://dx.doi.org/10.12804/revistas.urosario.edu.co/empresa/a.6525

Administradora de Empresas Universidad Autónoma de Bucaramanga-Colombia, Máster en Administración (UNAB Colombia-ITESM México), Auditor Iso 9000, Iso 14000 y OHSAS 18000 en el SGS, certificación en competencias UNAD, especialista en Educación con nuevas tecnologías Universidad Autónoma de Bucaramanga (Colombia), Diplôme Universitaire en Sciences de Gestion à l'université de Rouen-France. Profesor Ingeniería Industrial Universidad Industrial de Santander, Bucaramanga-Santander-Colombia.

Correo electrónico: mlramirez2006@yahoo.com 


\section{Resumen}

Este artículo busca mostrar las visiones estratégicas de los emprendedores sociales aplicadas en el Business Model Social, alrededor de una tipología articulada sobre tres grandes evoluciones que pertenecen al campo teórico: la primera es relativa al emprendimiento por medio de la escuela de la innovación social y la corriente de la intención estratégica (is) como herramienta de análisis para aprehender la diversidad estratégica de la empresa social, la cual cuenta con objetivos en el estudio de escogencias estratégicas de las organizaciones sociales. La segunda concierne a la movilidad de los recursos (Resource Based View "RBV") de las empresas sociales y las terceras son las escogencias estratégicas de las organizaciones sociales en el análisis de las visiones estratégicas de los dirigentes. La combinación de estos enfoques es articulada en una tipología de ocho categorías o escenarios del Business Model Social. El trabajo de campo es realizado por medio de un análisis cualitativo exploratorio fundado sobre el estudio de caso social, más particularmente ha sido seleccionada las asociaciones con fin lucrativo que buscan a la vez el beneficio económico y la realización de los objetivos sociales. Finalmente, ilustramos esta tipología sobre los factores predominantes de éxito en las organizaciones sanitarias y sociales que comprueba ser fuente de ventajas competitivas.

Palabras clave: Business Model Social, empresa social, visiones estratégicas, satisfacción del emprendedor social, tipología.

\section{The Strategic Visions of the Social Entrepreneurs in the Social Business Model: Proposition for a Typology Abstract}

This article aims at showing the strategic visions of the social entrepreneurs applied to the social business model about a typology articulated on three big evolutions that belong in the theoretical field: The first evolution is related to the entrepreneurship derived from the school of the social innovation and the flow of the strategic intention (si) as its analysis tool for apprehending the strategic diversity of the social enterprise, based on objectives in the study of strategic choices of the social organizations. The second one concerns to the resources mobilization (Resource Based View "RBV») of the social enterprises. And the third one is to the strategic chooses of the social organizations in the analysis of the leaders' strategic visions. The combination of these approaches is articulated by a typology of eight categories or scenarios of the social business model. A qualitative exploratory analysis founded on the study of social case, more particularly the associations have been selected by lucrative buts that look simultaneously for the economic benefit and the realization of social buts. In order to illustrate this typology on the predominant factors of success in the sanitary and social organizations that verified to be a source of competitive advantages.

Keywords: Social Business Model, social enterprise, strategic visions, satisfaction of the social entrepreneur, managerial continuity, scenario, typology.

\section{As visões estratégicas dos empreendedores sociais aplicadas no Social Business Model: proposta de uma tipologia Resumo}

Este artigo busca mostrar as visões estratégicas dos empreendedores sociais aplicadas no Social Business Model, ao redor de uma tipologia articulada sobre três grandes evoluções que pertencem ao campo teórico: a primeira aparição é relativa ao empreendimento por meio da escola da inovação social e a corrente da intenção estratégica (IS) como ferramenta de análise para apreender a diversidade estratégica da empresa social, a qual conta com objetivos no estudo de escolhas estratégicas das organizações sociais. A segunda aparição concerne a mobilidade dos recursos (Resource Based View "RBV") das empresas sociais e a terceira aparição são as escolhas estratégicas das organizações sociais na análise das visões estratégicas dos dirigentes. A combinação destes enfoques é articulada em uma tipologia de oito categorias ou cenários do Social Business Model. Uma análise qualitativa exploratória fundada sobre o estudo de caso social, mais particularmente tem sido selecionada as associações com fim lucrativo que buscam à sua vez o benefício económico e a realização dos objetivos sociais. Finalmente, ilustramos esta tipologia sobre os fatores predominantes de sucesso nas organizações sanitárias e sociais que comprova ser fonte de vantagens competitivas.

Palavras-chave: Social Business Model, Empresa Social, visões estratégicas, satisfação do empreendedor social, Tipologia. 


\section{Introducción}

Hoy, en un entorno complejo y turbulento donde la competencia se hace más importante y las alianzas estratégicas y el intercambio de información se desarrollan entre las empresas (nuevos modelos de creación de valor) (Normann \& Ramírez, 1993; Stabell \& Fjeldstad, 1998), se utiliza el término "redes de valor" para sustituir el de "cadenas de valor", y se puede utilizar la imagen, que toma todo su sentido aquí, según la cual «el pez más rápido se come al que es más lento».

Las organizaciones sociales en su estado ideal no tienen fines lucrativos, es decir, estas en su gran mayoría presentan fines sociales. Aunque es una obligación del Estado el funcionamiento de estas empresas sociales, la realidad es que este contribuye en una mínima parte en su sostenimiento. Sin embargo, estas organizaciones son mayoritariamente dependientes del Estado o de instituciones o fundaciones nacionales o internacionales para su funcionamiento. La tendencia lourde, que caracteriza subsidios del Estado, la empresa privada, los donantes o una cooperación internacional, les obligó a diversificar sus fuentes de financiación.

El modelo de negocios es asociado con los sectores de la nueva economía (Hedman \& Kalling, 2001), con el objetivo de desarrollar iniciativas para engendrar ingresos (Linder \& Cantrell, 2000; Mahadevan, 2000; Alt \& Zimmermann, 2001; Moyon, 2011; Demil \& Lecocq, 2008; Osterwalder, Pigneur \& Tucci, 2005). A este respecto, el Business Model permite crear valor a través de la propuesta y arquitectura hecha a sus clientes, con el fin de transformarlos en beneficios (ecuación de beneficios) (Moingeon \& Lehmann-Ortega, 2010; Moyon, 2011; Morris, Schindehutte \& Allen, 2005; Yunus, Moingeon \& Lehmann-Ortega, 2010; Demil \& Lecocq, 2010), profesionalizar sus recursos humanos asalariados y benévolos, atraer a nuevos socios, concebir estrategias de comunicación, reflexionar en términos de eficacia y de los resultados y no únicamente de medios, y colocar los pasos y el desempeño de la empresa sobre el mercado.

Las visiones estratégicas de los emprendedores sociales son conformadas por las estructuras sociales de la comunidad y nos enfocamos en las intenciones y escogencias 
que son afectadas por las presiones externas y su adaptación al entorno de la empresa social. Los emprendedores organizacionales disponen de diferentes tipos de visiones y, para cada uno de ellos, pueden tomar diferentes significados (Ramírez, 2010). En general, unos consideran su visión como un objeto que hay que alcanzar; otros, como la capacidad de ver aparecer algo en el largo plazo, y algunos otros como una imposibilidad o como la simple copia del vecino; sin embargo, cabe preguntarse, ¿cómo pueden ser concebidas las visiones de los emprendedores sociales? (Ramírez, 2011). Los dirigentes empresariales hacen frente a diversas situaciones, pero éstas no son totalmente idénticas, lo que requiere la introducción de la actividad inventiva y de la innovación para analizar la situación que vive la organización, estableciendo estrategias para poder hacer frente a cada situación que se presenta.

Las empresas sociales son conducidas por emprendedores sociales, los cuales disponen de la idea, la visión del negocio que hay que desarrollar y las estrategias para su conducta. De una parte, el concepto de «emprendedor social» es utilizado para designar a un pionero de una nueva idea, con un enfoque visionario y creativo para resolver los problemas reales del mundo Drayton (citado por Bornstein, 1998). Por otra parte, el emprendedor social debe crear un valor social y trabajar a favor del mejoramiento de la sociedad. Por otro lado, los emprendedores sociales son llamados fellows por Ashoka, ${ }^{1}$ y están llamados a a crear organizaciones en las que el éxito no es medido en límites de beneficio, sino con base en la transformación social; sus modelos son concebidos para ser copiados y ser reproducidos por el número más grande posible.

Los emprendedores sociales poseen características de visionarios, de liderazgo, de credibilidad y de integridad con una aptitud para generar compromiso, a través de valores sociales, como lo afirman Waddock y Post (1991, citados por Light, 2005). Además, tienen un papel de agentes de cambio del sector social, adoptando una misión para crear y para sostener un valor social, a la vez que buscan nuevas oportunidades (Dees, 1998).

Los emprendedores sociales perciben en sus misiones crear un valor social de mejor calidad que sus competidores, a través de comportamientos empresariales virtuosos de

\footnotetext{
La palabra Ashoka significa: «ausencia activa de tristeza». Ashoka es una asociación no gubernamental que busca atacar las miserias del mundo reparando y sosteniendo las iniciativas individuales de los emprendedores sociales en las organizaciones sociales, procurando producir un cambio profundo en la sociedad.
} 
los juicios equilibrados, pues exploran y reconocen oportunidades para la innovación, la proactividad y la toma de riesgo (Mort, Weerawardena \& Carnegie, 2002). Según Verstraete et Saporta (2006) proponen ver el Business Model (BM) como una etapa de la construcción del proyecto del emprendedor, como un punto no necesario del proceso de la empresa social a través de una idea, una oportunidad, un BM, una visión estratégica y un plan de negocios.

En efecto, las empresas, cuentan dentro de sus estructuras de funcionamientos, con un Business Model o un modelo de negocios (Warnier et al., 2004). El Business Model es un concepto muy utilizado por las empresas para describir su modo de funcionamiento, la modelización o la simplificación de la actividad de la empresa, así como su lógica de acción a través de la proposición de valor, la fabricación de valor y el modelo de ingresos.

Sin embargo, diversos autores en la literatura establecen diferencias para ayudar en la contribución de nuevos conceptos, permitiendo la definición sobre criterios observables de un tipo particular de Business Model, el llamado Business Model Social (BMS). Las empresas sociales con o sin fin lucrativo son las que se dan por misión la realización de los cambios sociales, la creación de un valor social y económico que responda a las necesidades no cubiertas por el entorno, con el fin de concebir, en función de los objetivos buscados, los modelos que hay que utilizar por los organismos sociales. A este título, es interesante saber si el Business Model (BM) sí se aplica en las mismas condiciones que las empresas con fin comercial. La problemática de las organizaciones del sector social justifica un estudio de estos Business Models Sociales, con el objetivo de percibir mejor las visiones estratégicas de los emprendedores sociales en el Business Model Social. Así, este estudio pretende responder a la pregunta siguiente, ¿cuáles son las diferentes configuraciones de Business Model Social empresarial, nacidas sobre las visiones estratégicas de los emprendedores sociales?

Este artículo será presentado en cuatro partes, apoyándonos en la articulación de los diferentes campos y las reflexiones teóricas de esta investigación. En la primera sección, proponemos un marco de análisis teórico o revisión de la literatura. Luego, en la segunda sección, una propuesta de una tipología conceptual sobre las visiones estratégicas de los emprendedores sociales en el Business Model Social (comparación de la literatura y la tipología propuesta). La tercera parte analiza teóricamente la metodología del estudio de 
caso. Finalmente, la cuarta sección ilustra los aportes de este artículo, que se generaron a partir de tres casos sociales exploratorios; estos resultados ponen en evidencia las implicaciones conceptuales y el retorno sobre la literatura.

\section{Marco de análisis teórico}

Es conveniente proceder a un análisis de la literatura para trazar una tipología del Business Model Social para identificar las temáticas retenidas de investigación. Así, en este marco de análisis teórico se realizará un examen de la literatura sobre el Business Model, la empresa social, su evolución y su tipología.

Los diversos autores trabajan en las visiones estratégicas de los emprendedores sociales y la formulación de las estrategias, así como en los modelos de negocios, concentrando la literatura utilizada sobre el sector privado para la creación de valor con lógica lucrativa, lo que genera ciertas vías y desviaciones, derivadas de las especificidades de estas organizaciones en la obtención de recursos. Sin embargo, presentan el proceso que sigue la creación de las estrategias, a través de la formulación y la colocación de las mismas (Mintzberg, Brian \& Voyer, 1995).

La pregunta es conocer el interés creciente en el estudio de las visiones estratégicas y la construcción de las concepciones diferentes por parte de los emprendedores sociales en el Business Model Social. Varias definiciones han sido propuestas y dependen de la perspectiva económica, financiera, estratégica, de gestión, etc. En los prolongamientos de los trabajos sobre el emprendimiento y sobre los enfoques teóricos, proponemos una visión global de Business Model Social de las empresas sociales, a partir de las dimensiones constitutivas en el sector social.

\subsection{Los elementos constitutivos de visiones estratégicas de los emprendedores sociales en el Business Model Social (BMS) a través del marco de análisis y los enfoques teóricos}

El análisis de los modelos configuracionales y en el modelo SMOCS nos permite distinguir tres dimensiones clave que recubren cada uno de los enfoques teóricos para comprender el emprendimiento (Smida, 2006), estos son el contexto, los objetivos de 
la empresa social y los recursos; también es necesario para su comprensión tener en cuenta las visiones estratégicas del emprendedor social sus competencias, sus recursos, y las oportunidades ofrecidas por el entorno externo.

Para analizar el fenómeno empresarial de la empresa social, Paturel (1997) propuso el modelo de las «3E». Se trata de un modelo integrador a través de tres dimensiones, que son las aspiraciones del emprendedor (E1), los recursos y las competencias en la empresa (E2) y el entorno externo (E3). A su vez, para analizar el Business Model Social, Paturel (2007) propuso el modelo de «3F», por medio de tres dimensiones: la eficacia de la empresa (F1), la proximidad entre los objetivos realizados y los objetivos fijados y la eficiencia de la empresa (F2), la manera a través de la cual los recursos y las competencias son utilizados para realizar los objetivos de la empresa, y la efectividad de la empresa (F3), la cual se concentra sobre la satisfacción de las partes interesadas o stakeholders que convergen en ella; estas tres dimensiones nos hablan entonces del entorno, la empresa y el emprendedor.

A partir de los modelos configuracionales de estos trabajos, se ponen en evidencia las tres dimensiones de base que conciernen al Business Model Social: la dimensión del entorno en los procesos del emprendimiento social, la dimensión organizacional, que se refiere a las características de la empresa social, y la dimensión individual, la cual integra las características personales del emprendedor social. Nuestra conceptualización se articula alrededor de los elementos siguientes: el contexto, los recursos y el objetivo de la empresa social.

\subsection{Fundamentos teóricos}

En la gestión, hacemos referencia a los términos de visión, empresa y líder o dirigente visionario, quien debe ser alguien capaz de dirigir sus negocios: la visión sería los mecanismos de conducta de la empresa en una perspectiva a largo plazo, pero no existe una definición precisa; proponemos un análisis de la literatura sobre este concepto (Ramírez, 2012). Algunos autores como Revolón (1999) distinguieron cuatro tipos de emprendedores: los emétropes, que son quienes pueden proyectar su empresa y el entorno; los hipermétropes, son aquellos que se orientan más hacia el entorno; los miopes débiles, son quienes proyectando su empresa no logran tener en cuenta el entorno, y los grandes miopes, que son quienes no proyectan ni su empresa, ni el entorno. Esta 
metáfora oftálmica es una manera original de aprehender la visión estratégica; a este respecto, Filion (1989; 1991), distingue la visión de la empresa como la visión interna y la visión del entorno como la visión externa.

Luego, conviene proceder sobre la articulación de los diferentes campos y reflexiones teóricas de esta investigación, alrededor de tres enfoques: la primera es relativa al contexto institucional en el estudio de las escogencias estratégicas de las organizaciones y la corriente de la intención estratégica de la empresa social. Para el segundo movilizamos los recursos de las empresas sociales y el tercero es relativo a las escogencias estratégicas de las organizaciones en el análisis de las visiones de los dirigentes para obtener la ventaja competitiva. A través de la combinación de estos tres enfoques es articulada una tipología de ocho categorías o escenarios de Business Model Social.

\subsubsection{Factores externos atados al contexto institucional en el estudio de las escogencias estratégicas de las organizaciones y la intención estratégica de la empresa social}

Según los enfoques centrados en el predominio del contexto, el pensamiento en estrategia de la empresa social se funda sobre la teoría de los recursos, la escuela de la innovación social y la escuela de la empresa social. Las teorías son inscritas por la dependencia de la empresa social que obtiene todos los recursos de las presiones del entorno y las estructuras sociales, de los éxitos de los emprendedores sociales en la conducta de sus empresas y de las fuerzas medioambientales que determinan la continuidad empresarial. Así, el contexto tiene un papel primordial por la diversidad de posicionamientos y de presiones del entorno, así como por ser el escenario en el que surgen las respuestas estratégicas, a través de las visiones de los emprendedores sociales que conducen a la elaboración de estrategias. El entorno externo está constituido por una diversidad de las organizaciones que forman parte del campo organizativo y desempeña un papel importante en la estrategia global de la empresa social. Más adelante presentaremos los elementos incontrolables del entorno, que forman parte del contexto social, el contexto regional, el institucional y el sectorial de la nueva empresa social, y que pueden influir sobre el proceso de supervivencia de la empresa social. 


\subsubsection{Factores internos atados sobre los recursos (RBV) de las empresas sociales}

El desempeño de las empresas sociales depende de los recursos con los que cuentan para su funcionamiento normal, del cual controla y presenta ciertas características específicas (Wernerfelt, 1984) como el valor, la rareza, la inimitabilidad y la no substentabilidad (Barney, 1991). Estas empresas se apoyan en una especificidad de los recursos provenientes del gobierno y también sobre los recursos por el valor social de los clientes, que son raros, inimitables y no sustituibles, como es el caso del precio por la prestación del servicio social (Barney, 1991). Estos recursos generan ventajas competitivas sustentables a las empresas sociales.

Ciertos trabajos probaron que integrar la dimensión social en el seno de la ecuación de beneficio (Yunus, Moingeon \& Lehmann-Ortega, 2010) es un factor clave de éxito en términos de supervivencia de la nueva empresa social. Las conexiones hechas por los emprendedores facilitan la consecución y conducta de recursos humanos y financieros, reforzando el desarrollo y la supervivencia de la empresa social (Jouison \& Verstraete, 2008). También, estos emprendedores sociales pueden con su credibilidad, acceder a la obtención de recursos externos por medio de la conexion de las diferentes partes interesadas y el contexto social en el Business Model Social.

\subsubsection{Factores atados a las escogencias estratégicas de las organizaciones sociales}

Una empresa debe conciliar su objetivo con los medios a través de la intención estratégica, es decir, alineando las estrategias de la empresa en la creación o el desarrollo de la organización social. La primera evolución de la estrategia ha sido demostrada por los trabajos de Porter (1980), con base en la industria, la competencia y la ventaja competitiva; aquí nos basamos en la intención estratégica, que es el elemento motor de la concepción de la visión, el cambio y la transformación de una organización (Hamel \& Prahalad, 1989). El análisis del entorno institucional desempeña un papel importante en la dinámica entre las organizaciones y las instituciones, como consecuencia de las escogencias estratégicas de esta interacción; estas escogencias estratégicas son determinadas por la emergencia de la visión fundada sobre la institución en función de sus estructuras formales e informales, su capacidad organizacional en la selección, la consecución de sus recursos específicos, y en el análisis de las dinámicas de las interacciones por las escogencias estratégicas (Peng, 2002). 


\subsubsection{Las dimensiones y las configuraciones de Business Model Social}

En la revisión de la literatura distinguimos tres dimensiones de Business Model Social (tabla 1), que son caracterizadas por su concepción y determinantes del Business Model Social. Proponemos un enfoque integrativo de estas tres dimensiones como respuesta a la Gestión Estratégica de Business Model Social.

Tabla 1. Tres dimensiones de las visiones de los emprendedores en los BMs y los fundamentos teóricos asociados

\begin{tabular}{|c|c|c|c|}
\hline Dimensiones & $\begin{array}{l}\text { Enfoque centrado sobre el } \\
\text { predominio del contexto }\end{array}$ & $\begin{array}{c}\text { Enfoque centrado sobre el } \\
\text { predominio de los objetivos } \\
\text { (estrategia) }\end{array}$ & $\begin{array}{l}\text { Enfoque centrado sobre } \\
\text { los recursos }\end{array}$ \\
\hline $\begin{array}{l}\text { Fondementos } \\
\text { teóricos }\end{array}$ & $\begin{array}{l}\text { EIS } \\
\text { La escuela de la } \\
\text { innovación social } \\
\text { (utilidad social). }\end{array}$ & $\begin{array}{c}\text { IS } \\
\text { La Intención Estratégica. }\end{array}$ & $\begin{array}{c}\text { RBV } \\
\text { La movilidad de los recursos } \\
\text { (Ressource-Based View). }\end{array}$ \\
\hline $\begin{array}{l}\text { Concepciones } \\
\text { de Business } \\
\text { Model Social } \\
\text { (BMS) }\end{array}$ & $\begin{array}{l}\text { La continuidad } \\
\text { empresarial de la } \\
\text { empresa social } \\
\text { Las presiones del entorno, } \\
\text { y las estructuras sociales. }\end{array}$ & $\begin{array}{c}\text { Las aspiraciones } \\
\text { del emprendedor del } \\
\text { sector social } \\
\text { A través de las visiones } \\
\text { en las condiciones para la } \\
\text { exploración. }\end{array}$ & $\begin{array}{l}\text { La debilidad económica } \\
\text { por los recursos } \\
\text { A través de la creación de recursos } \\
\text { en la capacidad de explotación y } \\
\text { la optimización de los recursos. }\end{array}$ \\
\hline $\begin{array}{l}\text { Determinantes } \\
\text { de Business } \\
\text { Model Social } \\
\text { (BMS) }\end{array}$ & $\begin{array}{l}\text { Contexto favorable } \\
\text { Factores del entorno } \\
\text { externo o el contexto. }\end{array}$ & $\begin{array}{c}\text { Objectivos de la } \\
\text { empresa social } \\
\text { La visión estratégica del } \\
\text { emprendedor social en la } \\
\text { determinación del éxito de la } \\
\text { empresa social. }\end{array}$ & $\begin{array}{l}\text { Disponibilidad de recursos } \\
\text { La carencia y la optimización de } \\
\text { los recursos en términos de capital } \\
\text { humano, social, y financiero. }\end{array}$ \\
\hline
\end{tabular}

Fuente: elaboración propia con base en Smida (1995), Paturel (1999; 2007), Osterwalder, Pigneur y Tucci (2005), Lecocq, Demil y Warnier (2006), Demil y Lecocq (2010), Mahadevan (2000), Jouison y Verstraete (2008).

El modelo SMOCS (Smida, 1995), nos muestra que es el lugar adaptado porque se apoya en la definición de la visión estratégica de los emprendedores sociales, es un modelo integrador según el plan de la visión de la estrategia. Tiene diferentes teorías que explican las tres dimensiones: el contexto, los objetivos y los medios. Responde a los enfoques estratégicos y nos permite soltar una visión tipológica. 


\section{Los escenarios o las categorías de las visiones estratégicas de los emprendedores sociales en el Business Model Social}

Los diversos trabajos sobre el emprendimiento se apoyan en un enfoque teórico, que tiene en cuenta los recursos, la estrategia, la intención estratégica y el objeto de estudio en la empresa social. Éstos muestran una visión global de los emprendedores sociales y una visión integrativa de tres dimensiones sociales de las empresas emergentes en el Business Model Social empresarial. Las tres dimensiones son la continuidad de la empresa social BMS*c, las aspiraciones del emprendedor del sector social BMS*Is y la debilidad económica por los recursos BMS*M. Estas dimensiones de Business Model Social se integran en las categorías de ocho configuraciones o escenarios de Business Model Social. Por medio de la realidad empírica -comprobada con la ayuda de las herramientas de colecta de los resultados empíricos de los escenarios (Smida, 1995; Paturel, 1997; 2007)- entre el BMS y el éxito total y el BMS y el fracaso total (tabla 2), propusimos las configuraciones de BMS marginal (tabla 3) y BMS parcial (tabla 4).

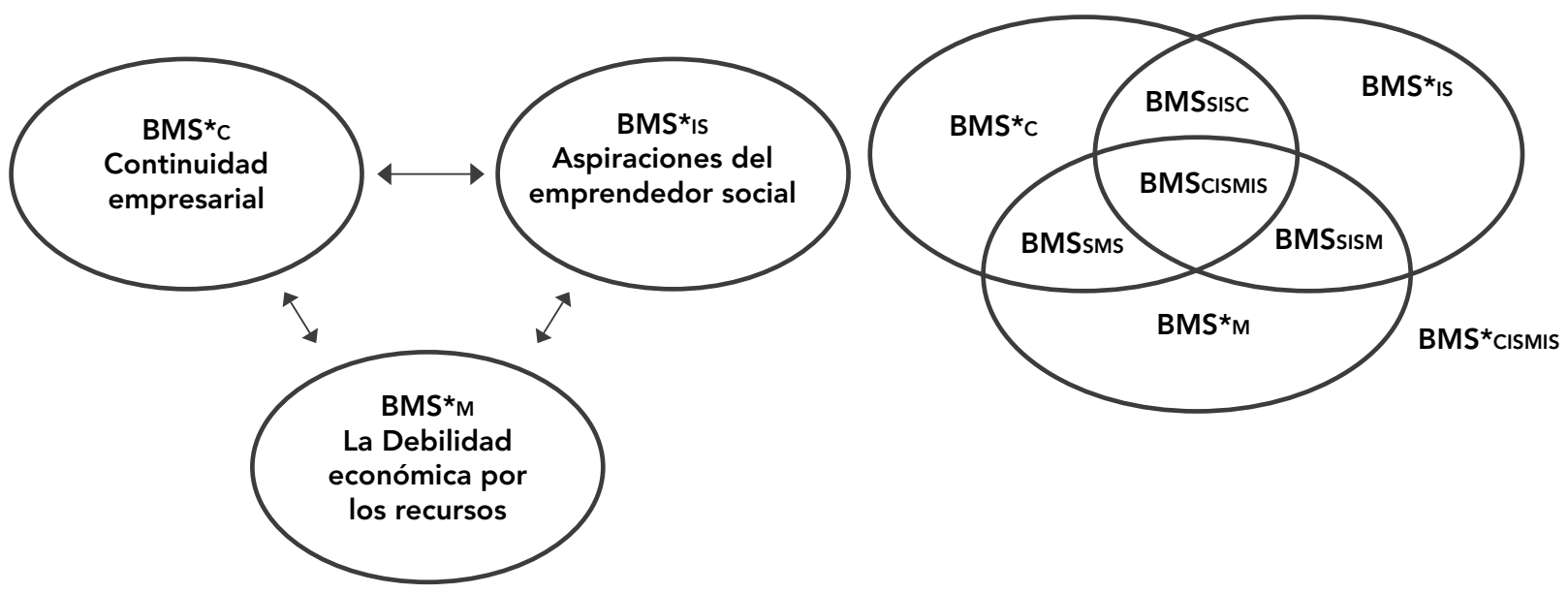

Figura 1. El enfoque integrativo de Business Model Social empresarial Fuente: elaboración propia. 


\subsection{Las configuraciones extremas de BMS éxito total (BMST) $y$ el BMS de fracaso total (BMS*T)}

Los tres espacios de Business Model Social son la continuidad de la empresa social BMS*C, las aspiraciones del emprendedor del sector social BMS*Is y la debilidad económica por los recursos BMS*M (figura 1). El espacio BMS*c reagrupa las empresas sociales que comienzan a ejercer su trabajo social, mientras que el espacio BMS*M reagrupa las empresas sociales que desaparecen por falta de recursos. El espacio BMS*IS reune las empresas sociales entre las que el fundador o el emprendedor social concretan sus aspiraciones y esperas iniciales en su proyecto de empresa y en su proyecto de vida, sus visiones y estrategias de estas organizaciones.

Tabla 2. Las configuraciones extremas de éxito o fracaso de Business Model Social

Categorías del BM social éxito total y fracaso total

Definiciones

\section{Configuración}

Los recursos con los que opera la empresa social (recursos humanos o financieros) que presta un servicio innovador; las intenciones estratégicas de los emprendedores sociales y las presiones ejercidas por el entorno para su continuidad empresarial. El emprendedor social tiene una visión de su Business Model Social o modelo de negocios, es un buen Business Model Social y un éxito empresarial.

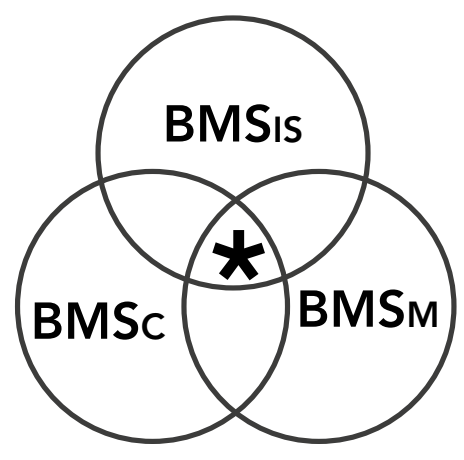

La empresa social no dispone de recursos BMS $_{\text {CISMIS: }}$ Fracaso Total de BMS Discontinuidad empresarial Ausencia de visión Falta de Recursos para la continuidad empresarial, el emprendedor social no dispone de visiones e innovación en la empresa social. No hay ninguna variable interna en la concepción de BMS. Esta situación conduce a una muerte y a un fracaso empresarial.

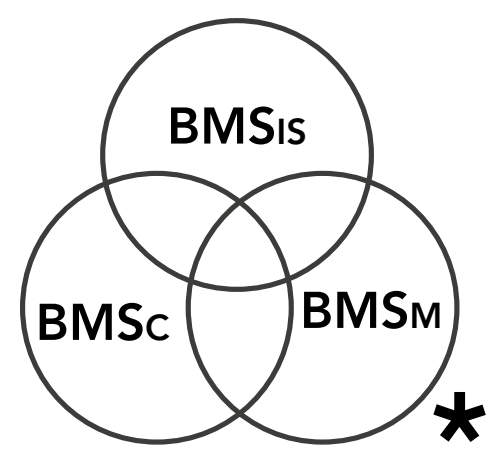

Fuente: elaboración propia. 


\subsubsection{La configuración de BMS éxito total (BMSCISMIS)}

La configuración de Business Model Social de éxito es definida alrededor de tres dimensiones: la continuidad de la empresa social $\mathrm{BMS}^{*} \mathrm{c}$, las aspiraciones del emprendedor del sector social BMS*Is y la debilidad económica por los recursos BMS*M (tabla 2); estos constituyen el espacio "CISMIs", que es explicado por el éxito de la empresa social, la cual recibe recursos del gobierno y genera recursos propios suficientes para su supervivencia. Este tipo de empresa social cuenta con todas las modalidades y los planes económicos para la creación de valor social. Los objetivos fijados son claros, el fundador o el emprendedor social cuenta con un proyecto de empresa y de vida que permite la visión para obtener el éxito total de Business Model Social.

\subsubsection{La configuración de BMS fracaso total (BMS* $\left.{ }^{*} I S M I S\right)$}

La configuración de tres espacios de Business Model Social de fracaso total (BMS*CISMIS) (tabla 2) esta definida alrededor de tres dimensiones: la discontinuidad empresarial BMS* $^{*}$, la ausencia de visión del emprendedor social BMS*IS y la debilidad económica por los recursos BMS*M. El fracaso de la empresa social se explica porque no tiene objetivos de salida y tiene dificultades en alcanzar su misión social; además, no cuenta con los recursos suficientes para sostener el desarrollo de su modelo de negocios.

\subsection{Las configuraciones de Business Model Social marginal (BMSMA)}

Entre las diferentes configuraciones de BMS éxito total y el BMS fracaso total existen diferentes casos de Business Model Social (tabla 3). Presentamos los escenarios BMS*IS, $\mathrm{BMS}^{*} \mathrm{C}, \mathrm{BMS}^{*} \mathrm{M}$. 
Tabla 3. Las categorías de Business Model Social marginal

\begin{tabular}{|c|c|c|}
\hline $\begin{array}{c}\text { Categorías del Business Model Social } \\
\text { Marginal }\end{array}$ & Definiciones & Configuración \\
\hline $\begin{array}{l}\text { BMS*IS: } \\
\text { Satisfacción del emprendedor social } \\
\text { Visión y comportamientos } \\
\text { Fallo de recursos } \\
\text { Discontinuidad empresarial }\end{array}$ & $\begin{array}{l}\text { Este escenario de BMS describe las } \\
\text { intenciones estratégicas de los empren- } \\
\text { dedores sociales por sus visiones con } \\
\text { la empresa social, a pesar del fallo de } \\
\text { recursos que genera la discontinuidad } \\
\text { empresarial. }\end{array}$ & \\
\hline $\begin{array}{l}\text { BMS*C: } \\
\text { Continuidad empresarial } \\
\text { Continuidad empresarial } \\
\text { Fallo de recursos } \\
\text { Falta de visión }\end{array}$ & $\begin{array}{l}\text { Este escenario de BMS describe la } \\
\text { situación del emprendedor social por } \\
\text { las presiones ejercidas desde el entorno } \\
\text { y por el contexto desde el cual opera la } \\
\text { empresa social, lo cual realiza de manera } \\
\text { estable para la continuidad empresarial; } \\
\text { sin embargo, en este caso el empren- } \\
\text { dedor social carece de visión y existe un } \\
\text { fallo de recursos para la empresa social. }\end{array}$ & \\
\hline $\begin{array}{l}\text { BMS }^{*} \text { M: } \\
\text { Creación de Recursos } \\
\text { Disponibilidad de Recursos } \\
\text { Discontinuidad empresarial } \\
\text { Falta de Visión y comportamientos }\end{array}$ & $\begin{array}{l}\text { Este escenario de BMS describe la dis- } \\
\text { ponibilidad de recursos para la empresa } \\
\text { social. Los recursos son superficiales pa- } \\
\text { ra la empresa social, y se logran a través } \\
\text { de un desempeño económico en el sub- } \\
\text { sidio de recursos, pero al emprendedor } \\
\text { social le falta una visión estratégica y hay } \\
\text { discontinuidad empresarial. }\end{array}$ & VISC \\
\hline
\end{tabular}

Fuente: elaboración propia.

\subsubsection{La configuración $B M S^{*} C$ de continuidad empresarial}

Las empresas sociales para su continuidad reciben ayudas financieras del gobierno, de la empresa privada, de donantes y de la cooperación internacional, pero las cantidades no son siempre suficientes para el desarrollo de sus actividades, y esto hace que los emprendedores sociales busquen estrategias diversas para facilitar la supervivencia de su empresa, mientras que ésta genere los beneficios al principio y obtenga una ventaja competitiva.

\subsubsection{La configuración BMS*IS: satisfacción del emprendedor social}

La empresa social posee los ingresos suficientes para el desarrollo normal de la actividad empresarial, lo que permite su continuidad sobre el mercado. El emprendedor 
social tiene una visión y un dinamismo concreto; sus aspiraciones empresariales y el plan de vida personal le permiten mostrar sus ideas.

\subsubsection{La configuración BMS* ${ }^{*}$ : la creación de recursos}

El espacio de creación de recursos para el seguimiento de la actividad empresarial como fuente de autosostenimiento de la empresa social y de su dirigente goza de una tranquilidad que permite la espera de los objetivos propuestos inicialmente.

\subsection{Las configuraciones de BMS parcial (BMSP)}

Las configuraciones de BMS parcial le presentan situaciones en dos de los tres espacios de Business Model Social: BMSc, BMSIs, BMSM. Las categorías o los escenarios son: BMSsisc, BMSsmc, BMSsism (tabla 4).

Tabla 4. Las categorías de Business Model Social parcial

\begin{tabular}{|c|c|c|}
\hline $\begin{array}{l}\text { Categorías del Business Model Social } \\
\text { parcial }\end{array}$ & Definiciones & Configuración \\
\hline $\begin{array}{l}\text { (CIS) } \\
\text { BMSsIsc: } \\
\text { Continuidad y visión } \\
\text { del emprendedor social } \\
\text { - Continuidad empresarial } \\
\text { - Visión del emprendedor } \\
\text { - Fallo de Recursos }\end{array}$ & $\begin{array}{l}\text { Este escenario de BMS analiza la situación } \\
\text { de la continuidad empresarial desde las } \\
\text { intenciones estratégicas y la visión del em- } \\
\text { prendedor social. El emprendedor busca } \\
\text { mantener la supervivencia y la innovación de } \\
\text { la empresa social, pero esta presenta el fallo } \\
\text { en la obtención de recursos por la rareza de } \\
\text { los mismos. }\end{array}$ & \\
\hline $\begin{array}{l}\text { (MC) } \\
\text { BMSsmc: } \\
\text { Continuidad con creación } \\
\text { de recursos } \\
\text { - Continuidad empresarial } \\
\text { - Disponibilidad de recursos } \\
\text { - Carencia de visión del emprendedor }\end{array}$ & $\begin{array}{l}\text { A pesar de las intenciones estratégicas y la } \\
\text { carencia de visión del emprendedor social, } \\
\text { la empresa social logra obtener una disponi- } \\
\text { bilidad de recursos para la innovación de los } \\
\text { servicios sociales; desde entonces, el contexto } \\
\text { por el cual opera la empresa social de manera } \\
\text { estable provoca su continuidad. }\end{array}$ & \\
\hline $\begin{array}{l}\text { (MIS) } \\
\text { BMSsIsm: } \\
\text { Supervivencia propia } \\
\text { - Discontinuidad empresarial } \\
\text { - Disponibilidad de recursos } \\
\text { - Visión del emprendedor social }\end{array}$ & $\begin{array}{l}\text { La empresa social logra generar ingresos } \\
\text { suficientes para asegurar su supervivencia } \\
\text { propia, gracias a la innovación permanente } \\
\text { bajo las intenciones estratégicas y la visión } \\
\text { del emprendedor social. El entorno de la } \\
\text { empresa social es parcialmente no rígido; } \\
\text { los recursos son homogéneos y de perfecta } \\
\text { movilidad, pero esta se ve afectada por la } \\
\text { discontinuidad empresarial. }\end{array}$ & \\
\hline
\end{tabular}

Fuente: elaboración propia. 


\subsubsection{La configuración BMSsisc de continuidad y visión del emprendedor social}

En esta categoría de Business Model Social, las empresas sociales logran generar ingresos suficientes, pero su fundador no está satisfecho del negocio y su plan personal porque no consigue alcanzar sus ambiciones y hay carencia de visión estratégica clave en la conducta de su modelo de negocios. En este caso, las empresas sociales, el estado o el gobierno, gracias a los recursos financieros externos movilizados, aportan su contribución para mantener en vida estas organizaciones sociales; el emprendedor social continúa su lucha para asegurar la continuidad empresarial y la supervivencia de su empresa social.

\subsubsection{La configuración BMSSMC de continuidad con creación de recursos}

El emprendedor concreta la continuidad de su empresa social y genera los ingresos suficientes en la actividad empresarial. A pesar de la carencia de visión del emprendedor social, la empresa logra obtener una disponibilidad de recursos, provocando su continuidad, es decir, los fondos que provienen del gobierno y los ingresos propios por la actividad empresarial aseguran el crecimiento y la perennidad de la empresa social. El emprendedor social tiene un interés en los objetivos económicos, obteniendo un negocio rentable, lo que genera tranquilidad y la supervivencia de la organización.

\subsubsection{La configuración BMSSISM de supervivencia propia}

La empresa social logra generar ingresos suficientes para asegurar su propia supervivencia con la visión y los comportamientos del emprendedor social, pero ella es afectada por la discontinuidad empresarial. La organización sobrevive sólo con su modelo de negocios, aunque tiene la capacidad de absorber el conocimiento adquirido para lograr el éxito de la empresa social. 


\section{Las categorías o los escenarios de las visiones estratégicas de los emprendedores sociales en el Business Model Social}

Explicaremos el contexto colombiano y nuestra escogencia metodológica. Después de haber precisado nuestro terreno de investigación, presentaremos los casos de Business Model Social y los aportes al terreno.

\subsection{El contexto colombiano}

Durante los últimos años, la generación de ingresos de las casas de ancianos en Colombia, como es el caso de las asociaciones que persiguen fines económicos y fines sociales, es más complicada; recoger los fondos suficientes para asegurar el funcionamiento de las obras se hace difícil por diversas razones nacionales, como la competencia de las instituciones para captar los recursos, los pocos donantes y la desviación de los recursos sociales del país; en el nivel internacional, el tema de la vejez no forma parte de las prioridades de cooperación mundial y los paises industrializados ignoran esa problemática local.

Según el enfoque fundado sobre los recursos, el problema económico es un fenómeno caracterizado por la situación financiera de la empresa social para la supervivencia de sus actividades en la cadena de valor. Las asociaciones como estas reciben una financiación por una asistencia social mínima por parte del gobierno, pero el importe de este subsidio depende de las necesidades y los ingresos; su concesión es acondicionada por la edad del beneficiario. Esto obligó a las organizaciones a comenzar a diversificar sus fuentes de financiación, desarrollando iniciativas para generar ingresos y profesionalizando los recursos humanos y el voluntariado para atraer a nuevos socios a estas organizaciones. Además, realizaron esquema de las estrategias de comunicación, una evaluación de los resultados y un desarrollo de la estructura de gestión que fuera más eficiente y eficaz. Hay una ausencia de barreras en la entrada, a través de la cual se limita la competencia y la nueva investigación de nuevas fuentes de financiación. Las casas de ancianos deben ser gestoras del régimen económico de funcionamiento, fijando un precio para la prestación del servicio social, en negociación con las diferentes ofertas o por medio de donantes, buscando un compromiso en los procesos organizacionales a través de las capacidades organizacionales. El objetivo fundamental de estas casas de ancianos es buscar el bienestar de las personas de edad. 
Por otra parte, los objetivos sociales son conflictivos, pues en una casa de ancianos los residentes están contra el aumento de los salarios del personal, bien sea para disminuir el importe que hay que pagar mensualmente o para dar la ocasión a esta casa de ancianos de maximizar los beneficios, creando así otros servicios que asegurarán el mejoramiento de sus cuidados. Por consiguiente, hay que reemplazar la realización de los objetivos sociales por la realización de uno o varios objetivos sociales.

Un emprendedor social comprometido con el cambio debe identificar las fuerzas de su empresa y desarrollarlas. Debe identificar los sectores estratégicos y moverse en éstos. Debe comprender las nuevas tendencias reinantes sobre el mercado global y preparar su empresa para que, en este contexto, pueda desarrollar nuevas ventajas competitivas (Hamel \& Prahalad, 1989). Debe saber sentir las oportunidades existentes sobre el mercado global, aprendiendo de los emprendedores con éxito. Debe poder liberarse de procedimientos tradicionales, tener la capacidad de optimizar las cosas que sabe hacer, y reconocer las oportunidades que otros no descubrieron. Además, debe cambiar rápidamente de estrategia, cuando es necesario, aprovechar y aprender del éxito y los fracasos de otros, y simplificar las cosas complejas. Debe crear orden donde reina el caos en la organización y remediar los problemas derivados de una falta de información apropiada y oportuna.

La sostenibilidad económica de una organización depende de las visiones y de los comportamientos estratégicos de los emprendedores sociales y de su capacidad de mantener las relaciones sociales que le dan los recursos y el apoyo, a través del mantenimiento del capital necesario para el desarrollo de sus procesos o el abastecimiento propio de autonomía, obteniéndo los fondos por medio de propuestas de valor al consumidor que se mantienen, en cambio, sin depender de partes interesadas (stakebolders), presentando un compromiso social.

El nuevo emprendedor social, especialmente de las empresas sociales nuevas, emergentes y promisorias, debe tener una nueva visión, una mirada sagaz, para adaptarse en el laberinto cambiante y complicado del mercado actual.

El Business Model Social de la empresa social colombiana presenta varias condiciones particulares, por ejemplo, cuenta con un estatuto jurídico legalmente constituido, tiene una contabilidad y maneja un balance y libros contables; las empresas sociales cuentan con 
estatutos jurídicos legalmente constituidos sobre los cuales los emprendedores sociales pueden beneficiarse de ventajas fiscales. Además, todos los movimientos contables en el balance general y los libros contables que generan el negocio: (1) los activos y las inversiones, como los bienes mobiliarios o inmobiliarios, (2) los pasivos, los cuales son todos los gastos engendrados, y (3) el patrimonio, que es el capital invertido para sus modelos de negocios sociales. Todo esto se basa en los decretos de la legislación colombiana.

\subsection{Metodología de investigación}

\subsubsection{El estudio de caso social cualitativo}

Este artículo se desarrolla en un marco interpretativo, confrontando el marco teórico a través de la exploración de las visiones estratégicas de los emprendedores sociales en el Business Model Social y la dinámica empresarial en un terreno de estudio de la empresa social; el marco de referencia es exploratorio para repetir y analizar los datos.

Para ilustrar los escenarios de Business Model Social, ponemos en evidencia el modelo SMOCS (estrategias de medios, los objetivos, las restricciones y los escenarios) (Smida, 1992; 1995). Este modelo trabaja sobre la teoría de los conjuntos, la modelización de un diagrama de VENN, las situaciones actuales y los escenarios futuros de la empresa (Smida, 1992). Así, se puede estudiar la dinámica empresarial y la modelización por medio del diagrama de VENN y de las estrategias que los emprendedores adoptan asocidas al fracaso (Smida \& Khelil, 2010).

Tenemos el estudio de caso exploratorio (Yin, 1990) que pretende verificar las categorías presentadas por la literatura. Nuestra intención no es mostrar la veracidad de las categorías obtenidas detalladas anteriormente, sino poder ilustrar y dar un análisis de las diferentes configuraciones teóricas y disponer de una serie de casos sociales construidos dentro de la empresa social para comprender las visiones estratégicas de los emprendedores sociales y desarrollar una unidad de análisis que permite abordar la Gestión Estratégica de Business Model Social.

\subsubsection{Constitución de la muestra de caso social}

Seleccionamos tres casos de casas de ancianos según el criterio de asociaciones con fines lucrativos y sociales y escogimos al emprendedor social para mostrar sus experiencias en los modelos de negocios. Los tres casos sociales constituyen un terreno de 
estudio para ilustrar las diferentes configuraciones conceptuales de Business Model Social. Utilizamos dos principios fundamentales de estos casos sociales:

1. Un estudio exploratorio sobre un fenómeno dentro del contexto de vida se realiza por medio de la integración y de la comprensión de un fenómeno social, basado en una variedad de fuentes de datos Yin (2003).

2. La selección del modelo de negocios a partir de las revisiones documentales y las entrevistas al emprendedor social seleccionado para el estudio.

\subsubsection{Método de recopilación de los datos}

Para la recopilación de los datos, preparamos una guía de preguntas al emprendedor social, que han sido realizadas cara a cara por medio de respuestas libres para que los entrevistados expresaran abiertamente sus opiniones y sentimientos, y pudieramos conocer su modelo de negocio social, a través de organizaciones del sector sanitario y social colombiano. La duración de esta entrevista fué de 45 minutos. Nos limitamos a tres casos de empresas sociales. Según, Yin (2003) el carácter del caso es un caso extremo, raro, crítico e interesante; los recursos y particularidades atadas al hecho reúnen las condiciones particulares de un fenómeno histórico y revelador de los procesos organizacionales.

Las preguntas fueron, ¿cuáles son las causas de éxito de la casa de ancianos como empresa social? A partir de ella, el emprendedor social presenta una lista de factores externos e internos en el Business Model Social y responde a una serie de preguntas: ¿cuáles son los factores que muestran el crecimiento y el desarrollo de su modelo de negocio en la empresa social?, ¿cuál es su visión futura del Business Model Social?, ¿cuáles dificultades encontró con los modelos de negocios? El emprendedor social también responde a otras cuestiones como ¿cuáles fueron los cambios con los que usted se enfrentó en la empresa social para conseguir? La colecta de los datos cualitativos es completada por los documentos internos de la empresa social; los datos de discurso de los emprendedores sociales han sido reagrupados en frases que hacen emerger las dimensiones constitutivas del Business Model Social estudiado.

La segmentación temática permitió categorizar los datos por medio de componentes y reagrupó totalmente los elementos conceptuales reducidos a mantener su empresa social y las estrategias utilizadas en la continuidad empresarial, las cuales nos permitieron poner 
en evidencia también los éxitos obtenidos (Miles \& Huberman, 2003). El análisis empírico será hecho en concordancia con la teoría; es necesario resaltar que este estudio ha sido realizado en un caso específico, pero puede ser extrapolado a otros terrenos de investigación.

\section{Resultados}

\subsection{Análisis de los casos sociales y los aportes al terreno}

Los escenarios presentados aquí corresponden a varias casas de ancianos diferentes. Estudiamos en nuestra fase exploratoria tres casas de ancianos independientes, donde existen factores de éxito dentro de estas casas. Presentamos, luego, los factores de éxito en 8 escenarios posibles en los cuales los emprendedores sociales se encuentran inmersos: el marco teórico y la categoría teórica propuesta, las visiones estratégicas del emprendedor social en el Business Model Social, permitió ilustrar el caso de la casa de ancianos en Colombia (tabla 5).

Tabla 5. El caso de la casa de ancianos según las tres dimensiones de Business Model Social

\begin{tabular}{ccc}
$\begin{array}{c}\text { Continuidad } \\
\text { empresarial }\end{array}$ & $\begin{array}{c}\text { Aspiraciones del } \\
\text { emprendedor } \\
\text { del sector social }\end{array}$ & $\begin{array}{c}\text { Debilidad económica } \\
\text { por los recursos y } \\
\text { la disponibilidad de } \\
\text { recursos }\end{array}$ \\
\hline
\end{tabular}

\begin{tabular}{|c|c|c|c|c|}
\hline Caso Casa de los Recuerdos & C & 0 & 0 & BMSc \\
\hline Caso FAVAC & 0 & IS & 0 & BMSIS \\
\hline Caso Ruitoque Casa Mayor & 0 & 0 & M & BMSM \\
\hline Caso Ruitoque Casa Mayor & 0 & IS & M & BMSSISM \\
\hline Caso FAVAC & C & 0 & M & BMSsmc \\
\hline Caso Ruitoque Casa Mayor & C & IS & 0 & BMSsIsC \\
\hline Caso FAVAC y Ruitoque Casa Mayor & C & IS & M & BMS CISMIS \\
\hline Caso Casa de los Recuerdos & 0 & 0 & 0 & $\mathrm{BMS}^{*} \mathrm{CISMIS}$ \\
\hline
\end{tabular}

Fuente: elaboración propia con base en los casos Casa de los Recuerdos, FAVAC y Ruitoque Casa Mayor. 
- El éxito empresarial de Business Model Social a través de la supervivencia de la empresa social: Los casos sociales estudiados en esta investigación son los de la Casa de los Recuerdos (BMSc), FAVAC (BMSIS) y Ruitoque Casa Mayor (BMSM) que corresponden a la conjunción de tres dimensiones: la continuidad empresarial, la deficiencia económica por los recursos y las aspiraciones del emprendedor del sector social. La investigación de los casos sociales muestra dos dimensiones preponderantes de Business Model Social, una económica y otra afectiva. Según la teoría de recursos (RBV) de la empresa social, éstos esencialmente son utilizados en fines personales, en la continuidad y el crecimiento de la actividad empresarial. El papel del gerente en el enfoque de la escuela de la innovación social y el objeto de estudio en la Empresa Social tiene en cuenta la intención estratégica de Hamel y Prahalad (1989) y según Filion (1989; 1991) las visiones, la racionalidad calculadora y la capacidad de administrar y negociar con su entorno social. Finalmente, hay que añadir su nivel de apropiación con relación a las escogencias estratégicas, si las aspiraciones del dirigente son orientadas hacia la maximización del beneficio económico y la maximización del beneficio social por el servicio social con sus clientes. El emprendedor pasa por momentos de motivación, una satisfacción en la continuidad de las empresas sociales; desde entonces, su visión, su voluntad y su determinación permiten sostener sus empresas sobre el mercado. 


\subsubsection{La repartición del caso de estudio entre las diferentes configuraciones de Business Model Social}

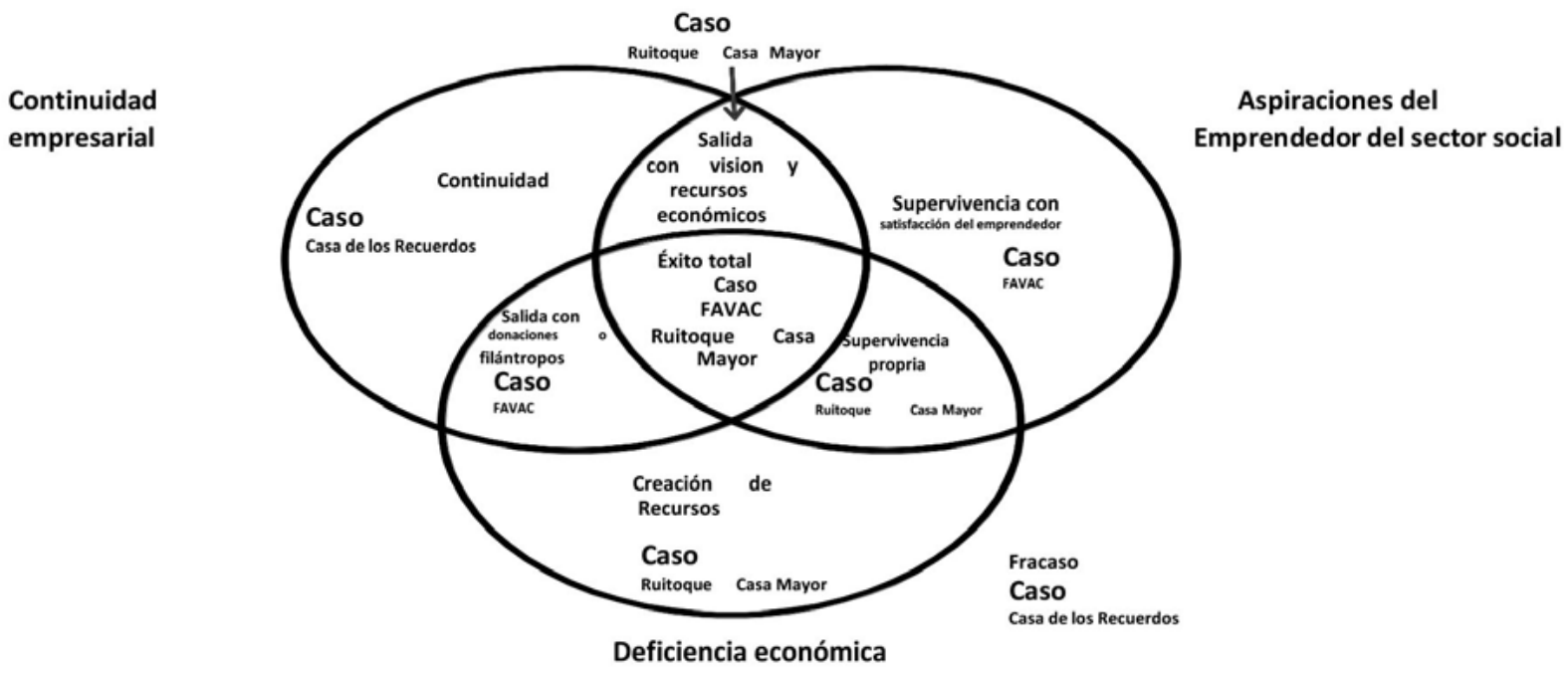

Figura 2. Las configuraciones de Business Model Social en los casos Sociales

Fuente: elaboración propia con base en los casos Casa de los Recuerdos, FAVAC y Ruitoque Casa Mayor.

- El caso social FAVAC BMSsmc (personas de edad sin capacidades financieras): Esta empresa genera beneficios sociales y puede lograr buscar fondos por medio de donaciones, filántropos nacionales y cooperación internacional con ayuda mínima del Estado. El caso social es centrado sobre el enfoque fundado sobre la teoría de recursos.

- El caso social Ruitoque Casa Mayor BMSsisc: En ella ha sido fundamental la decisión de la continuidad de la empresa social, para poder conseguir su autonomía por medio de la creación de recursos económicos con la construcción de la casa de ancianos Ruitoque Casa Mayor (personas de edad con capacidades financieras). Así, el emprendedor social cuenta con visiones, mostrando la visión de la empresa como la visión interna y la visión del entorno como la visión externa (Filion, 1989; 1991). El caso es fundado sobre el enfoque basado en las estrategias.

- El caso social Ruitoque Casa Mayor BMSsism: En cuando a aspiraciones y recursos, los emprendedores a cargo de la construcción de la casa de ancianos Ruitoque Casa Mayor, muestran su satisfacción; en efecto, encuentran oportunidades en la creación de recursos propios, con el fin de cumplir los objetivos propuestos en sus misiones sociales. El caso social está basado en la teoría de los recursos. 
- En los casos sociales FAVAC y Ruitoque Casa Mayor BMScismis: El emprendedor social cuenta con visiones generadas con base en la teoría de los recursos (RBV), ya que ambas empresas sociales tienen recursos económicos para su propia supervivencia. Así, el caso social Ruitoque Casa Mayor se apoya en un enfoque de éxito, pues la empresa social llega a su propia supervivencia, lo que permite concluir que el caso social es visto, según un ángulo del enfoque fundado sobre los recursos como un caso de éxito. Según la corriente de la intención estratégica (Hamel \& Prahalad, 1989), éste es el elemento motor de la concepción de la visión, el cambio y la transformación de una organización y, en efecto, es interpretado como un éxito. La empresa social FAVAC cuenta con solvencia económica para el desarrollo de sus actividades en la cadena de valor, haciendo que la organización conserve su ventaja competitiva (Porter, 1985). Los casos sociales FAVAC y Ruitoque Casa Mayor son un éxito de Business Model Social.

- El Caso social de fracaso: La situación cambia con el centro vida la Casa de los Recuerdos ya que el entorno institucional ejerció una presión negativa sobre el estudio de la organización (Peng, 2009). A pesar del éxito económico y el apoyo en los procesos internos en su modelo de negocio, los problemas sociales externos en la organización influyen enormemente y pueden, en un plazo, conducir a su fracaso: esto obligó a la empresa a acabar sus actividades y a abandonar lo que había sido construido a causa de las amenazas de la guerrilla. El caso social de la Casa de los Recuerdos ilustra el escenario BMS*CISMIS y es interpretado como un fracaso, pues la empresa no logró tener una continuación en el mercado. Sin embargo según el enfoque fundado sobre la escuela de la innovación social y el objeto de estudio en la empresa social, este caso es considerado como un fracaso. Presentamos, a continuación las características predominantes del emprendedor social dentro de los casos sociales. 
Tabla 6. Características predominantes de los casos sociales

\begin{tabular}{|c|c|}
\hline $\begin{array}{l}\text { Nombre de la } \\
\text { empresa social }\end{array}$ & Características predominantes \\
\hline $\begin{array}{l}\text { Caso social } \\
\text { Casa de los Recuerdos BMSC }\end{array}$ & $\begin{array}{l}\text { - Relaciones con los actores externos. } \\
\text { - Recursos financieros. } \\
\text { - Afecto del emprendedor social. } \\
\text { - Experiencia y conocimiento de las actividades. } \\
\text { - Apoyo económico. } \\
\text { - Número de empleados en la cocina. }\end{array}$ \\
\hline Caso social FAVAC BMSIS & $\begin{array}{l}\text { - Relaciones con actores externos. } \\
\text { - Proyecto de formación en valores para los Ángeles Custodios. } \\
\text { - Afecto del emprendedor social. } \\
\text { - Ambiciones de crecimiento y de desarrollo. } \\
\text { - Modelo intergeneracional (niños - personas de edad). } \\
\text { - Experiencia profesional en la atención de personas de edad. } \\
\text { - Reconocimiento por la labor social. } \\
\text { - Proyecto de vida personal del emprendedor social. }\end{array}$ \\
\hline $\begin{array}{l}\text { Caso social Ruitoque } \\
\text { Casa Mayor BMSM }\end{array}$ & $\begin{array}{l}\text { - Infraestructura arquitectónica. } \\
\text { - Unidad estratégica de negocios. } \\
\text { - Modelo de gestión y atención de personas de edad. } \\
\text { - Modelo intergeneracional (niños - personas de edad). } \\
\text { - Redes sociales. } \\
\text { - Cambios culturales. } \\
\text { - Complejidad en la terminación de la obra social. }\end{array}$ \\
\hline $\begin{array}{l}\text { Caso social Ruitoque } \\
\text { Casa Mayor BMSsIsM }\end{array}$ & $\begin{array}{l}\text { - Defensa propia. } \\
\text { - Transferencia de recursos económicos en FAVAC. } \\
\text { - Estructura de costos y márgenes de utilidad. } \\
\text { - Experiencia profesional en la atención de personas de edad. } \\
\text { - Proyecto de vida personal y calidad de vida. } \\
\text { - Prestación del servicio para los altos estratos socioeconómicos. }\end{array}$ \\
\hline Caso social FAVAC BMSsmC & $\begin{array}{l}\text { - Continuidad de la actividad empresarial. } \\
\text { - Recursos económicos pocos por parte del Estado. } \\
\text { - Donaciones de la empresa privada y los benévolos. } \\
\text { - Cooperación internacional. }\end{array}$ \\
\hline $\begin{array}{l}\text { Caso social Ruitoque } \\
\text { Casa Mayor BMSsisc }\end{array}$ & $\begin{array}{l}\text { - Generación de recursos propios. } \\
\text { - Relaciones relacionales. } \\
\text { - Competencia de las empresas sociales ya establecidas. } \\
\text { - Nuevas estructuras financieras. } \\
\text { - Experiencia en el sector social. } \\
\text { - Inclusión de colaboradores }\end{array}$ \\
\hline
\end{tabular}




\begin{tabular}{|c|c|}
\hline $\begin{array}{l}\text { Nombre de la } \\
\text { empresa social }\end{array}$ & Características predominantes. \\
\hline $\begin{array}{l}\text { Casos sociales FAVAC } \\
\text { y Ruitoque Casa Mayor } \\
\text { BMScIsmis }\end{array}$ & $\begin{array}{l}\text { - } \text { Redes sociales del fundador. } \\
\text { - } \text { Estructura de costos y margen de utilidad. } \\
\text { - } \text { Sostenimilidad con los clientes. } \\
\text { - } \text { Experiencia en el dominio de la actividad social. } \\
\text { - Reconocimiento en el sector social. } \\
\text { - Recursos financieros. } \\
\text { - Tiempo consagrado del emprendedor social en la vida de } \\
\text { (las personas de edad). }\end{array}$ \\
\hline 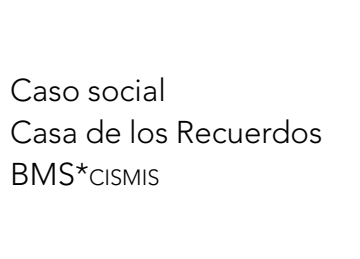 & $\begin{array}{l}\text { - Problemas de inseguridad. } \\
\text { - Presiones institucionales. } \\
\text { - Problemas financieros. } \\
\text { - } \text { Fondos insuficientes. } \\
\text { - Cierre de la actividad social. }\end{array}$ \\
\hline
\end{tabular}

Fuente: elaboración propia con base en los casos Casa de los Recuerdos, FAVAC, Ruitoque Casa Mayor.

\subsubsection{La categoría teórica de Business Model Social propuesta, nos permite mostrar cuatro escenarios posibles y contemplar cuatro trayectorias posibles (figura 3).}

A través de la movilización de nuestro marco teórico y de la categoría propuesta, el Business Model Social permanece estático. Permite presentar a las empresas sociales para el éxito empresarial con una grilla de lectura teórica. Los estudios de casos sociales permitieron mostrar las diversas formas de éxito de sus modelos de negocios para obtener la maximización del beneficio económico y del beneficio social a través de una salida negativa (no hay inversión de capital) o de una salida positiva (Inversión de capital). 


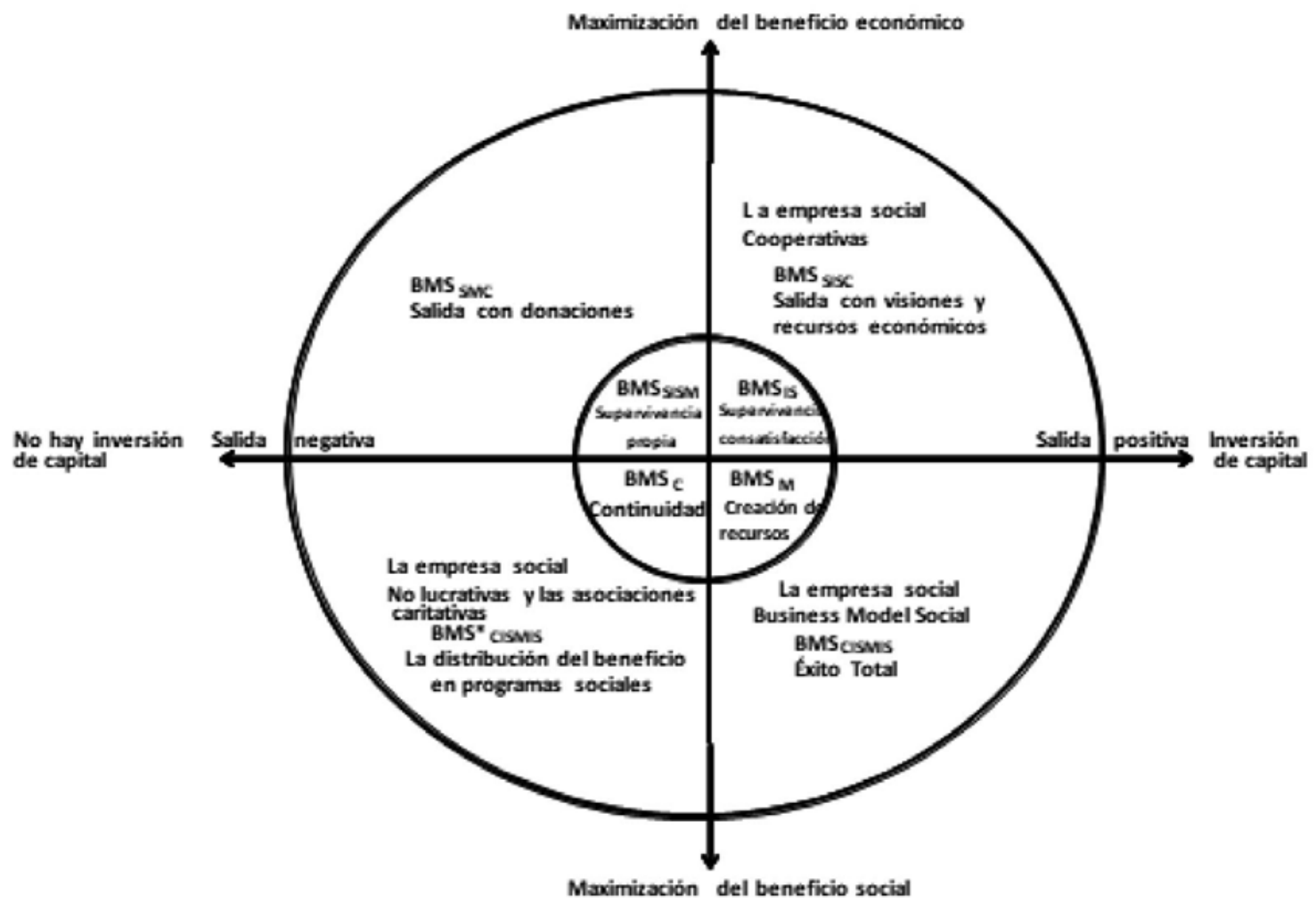

Figura 3. Las cuatro trayectorias de Business Model Social

Fuente: elaboración propia con base en Defourny (2001), Yunus, Moingeon y Lehmann-Ortega (2010), Defourny y Nyssens (2011).

Esta trayectoria no presenta beneficios para las empresas sociales. Ellas reciben dinero del gobierno y sufren presiones institucionales que llegan al cierre de la empresa social, como sucedió en el caso de la Casa de los Recuerdos (trayectoria 1). En el caso FAVAC, la empresa social logra satisfacer sus necesidades por medio de donaciones, filántropos y partes interesadas (stakebolders), además de obtener una participación ínfima del Estado, que invierte dinero para el desarrollo de sus actividades (trayectoria 2). El caso de Ruitoque Casa Mayor tiene una supervivencia que satisfacen los emprendedores sociales (trayectoria 3). Los casos sociales FAVAC y Ruitoque Casa Mayor son un éxito total, pues generan recursos económicos y fines sociales en el Business Model Social (trayectoria 4), lo que genera su continuidad en el mercado. Nos apoyamos en las categorías propuestas en el marco teórico sobre el Business Model Social, para así presentar los resultados del estudio de caso exploratorio, los cuales permitieron identificar las visiones del emprendedor social asociadas con la continuidad de las empresas sociales en sus modelos de negocio. El emprendedor social mostró el éxito de Business Model Social a través del 
éxito económico influenciado por la dimensión afectiva como el éxito de satisfacciones personales de sus organizaciones sociales.

\section{Conclusiones}

Presentamos en este artículo un marco analítico, respondiendo a las reflexiones teóricas de nuestra problemática. El recurso en el modelo SMOCS (Smida, 1992; 1995; 2006; 2007), el modelo 3E y 3F (Paturel, 1997; 2007) propone un análisis conceptual y tipológico de Business Model Social. Para comprender mejor los determinantes del Business Model Social, mostramos una tipología en ocho configuraciones conceptuales, a partir de un marco teórico integrador que cuenta con tres dimensiones del Business Model Social: la escuela de la innovación social, el objeto de estudio en la Empresa Social y el enfoque fundado sobre los recursos y la intención estratégica; en último lugar, el estudio mostró las visiones estratégicas de los emprendedores sociales en el Business Model Social.

Las empresas sociales adoptan escogencias estratégicas a través de las visiones de los dirigentes para adaptarse a las dinámicas del entorno institucional, es por eso que hay que envolver una respuesta estratégica apropiada. Integramos tres enfoques: el primer enfoque es la continuidad de la actividad empresarial, el segundo enfoque muestra cuáles son las aspiraciones del emprendedor del sector social con base en su visión, el tercer enfoque es la deficiencia de la empresa social en la consecución de recursos fundamentales sobre la primacía de los recursos.

Quisimos mostrar una descripción breve y general de los diversos métodos que los emprendedores sociales utilizan comúnmente para identificar los problemas, las soluciones y los planes de acción en las empresas sociales. Esta tipología muestra los aspectos integradores, pero no son dinámicos, sino estáticos en nuestro marco de análisis movilizado. Extrapolando lo que acaba de decirse, podemos concluir que cada emprendedor organizacional tiene su visión particular de la realidad y su modo de actuar frente al futuro de su propia empresa. Algunos métodos existen y lo que debe hacer un emprendedor es buscar el mejor de ellos y adaptarlo a su propia idea. La reflexión de este estudio contribuye al desarrollo de los emprendedores, pues todos los métodos expuestos logran llegar a ella a través de preguntas, y su desarrollo marca el paso a seguir para cada uno de ellos. 


\section{Referencias}

Alt, R., \& Zimmermann, H.D. (2001). Preface: Introduction to Special Section on Business Models. Electron Mark, 11(1), 3-9.

Barney, J.B. (1991). Firm Resources and Sustained Competitive Advantage. Journal of Management,17(1), 99-120.

Bornstein, D. (1998). Changing the World on a Shoestring. The Atlantic Monthly, 281(1), 34-39.

Dees, G. (1998). Enterprising Nonprofits. Harvard Business Review, 76(1), 55-67.

Defourny, J. (2001). From Third Sector to Social Enterprise. In Borzaga C. \& Defourny J. (Eds.), The emergence of social enterprise, London and New York: Routledge.

Defourny, J., \& Nyssens, M. (2011). Approches Européennes et Américaines de l'Entreprise Social: une perspective comparative. Revue Internationale de l'Économie Sociale: Recma, Revue des Études Coopératives, Mutualistes et Associatives, (319), 18-35.

Demil, B., \& Lecocq, X. (2008). Repenser le développement des organisations: les apports du modèle économique. Revue Française de Gestion, 34(181), 113-122.

Demil, B., \& Lecocq X. (2010). Business Model Evolution: In Search of Dynamic Consistency. Long Range Planning, 43(2-3), 227-246.

Filion, L.J. (1989). Le développement d'une vision: un outil stratégique à maîtriser. Gestion, 14(3), 24-34.

Filion, L.J. (1991). Vision et relations: clefs du succès de l'entrepreneur. Montreal: Editions de l'entrepreneur.

Hamel, G., \& Prahalad, C.K. (1989). Strategic Intent. Harvard Business Review, 83(7), 148-161.

Hedman, J., \& Kalling, T. (2001). The Business Model: a Means to Understand the Business Context of Information and Communication Technology. Working Paper, School of Economics and Management: Institute of Economic Research.

Jouison, E., \& Verstraete, T. (2008). Business Model et Création d'Entreprise. Revue Française de Gestion, 35(181), 175-197.

Lecocq, X., Demil, B., \& Warnier, V. (2006). Le Business Model, un Outil d'Analyse Stratégique. L'Expansion Management Review, (123), 96-109.

Light, P. (november, 2005). Searching for Social Entrepreneurs: Who They Might Be, Where They Might Be Found, What They Do. Annual Conference Association for Research on Nonprofit and Voluntary Associations, New York University. 
Linder, J., \& Cantrell, S. (2000). Changing Business Models: Surveying the landscape. Working Paper, Accenture Institute for Strategic Change.

Mahadevan, B. (2000). Business Models for Internet-Based e-Commerce: An Anatomy. California Management Review, 42(4), 55-69.

Miles, M.B., \& Huberman, A.M. (2003). Analyse des Données Qualitatives (Segunda edición). Bruxelles: De Boeck.

Mintzberg, H., Brian, J., \& Voyer, J. (1995). The Strategy Process. Englewood Cliffs, N.J.: Prentice-Hall.

Moingeon B., \& Lehmann-Ortega, L. (2010). Genèse et Déploiement d'un Nouveau Business Model: L'étude d'un cas Désarmant. Management, 13(4), 266-297.

Morris, M., Schindehutte, M., \& Allen J. (2005). The Entrepreneur's Business Model: Toward a Unified Perspective. Journal of Business Research, 58(6), 726-735.

Mort, G., Weerawardena, J., \& Carnegie, K. (2002). Social Entrepreneurship: Towards Conceptualization and Measurement. American Marketing Association Conference Proceedings, Chicago, Illinois.

Moyon, E. (2011). Le changement du Business Model de l'Entreprise: une étude des majors de l'industrie phonographique (1998-2008). Lille, Economie \& Management: Université Lille 1, Institut d'Administration des Entreprises.

Normann, R., \& Ramírez, R. (1993). From Value Chain to Value Constellation: Designing Interactive Strategy. Harvard Business Review, 71(4), 65-77.

Osterwalder, A., Pigneur Y., \& Tucci, C.L. (2005). Clarifying Business Models: Origins, Present, and Future of the Concept. Communications of the Association for Information Systems, 15(16), 1-25.

Paturel, R. (1997). Pratique du management stratégique. Les processus de la création d'entreprise. Grenoble: Presses Universitaires de Grenoble.

Paturel, R. (2007). Démarche stratégique et performance de la PME. En L.J. Filion (dir.). Management des PME: De la création à la croissance (pp. 429-443). Montréal: Éditions du Renouveau Pédagogique.

Peng, M. W. (2002). Towards an Institution-Based View of Business Strategy. Asia Pacific Journal of Management, 19(2-3), 251-267.

Peng, M.W. (2009). Global Strategy (Segunda edición.). Cincinnati: South-Western Cengage Learning.

Porter, M. (1980). Choix stratégiques et concurrence: Technique d'analyse des secteurs et de la concurrence dans l'industrie. Gestion. Harvard Business School: éditions Economica. 
Porter, M. (1980). Competitive Strategy. New York: The Free Press.

Porter M.E. (1985). The Competitive Advantage: Creating and Sustaining Superior Performance, New York: The Free Press.

Ramírez, M. (octubre, 2010). La visión estratégica como instrumento para el cambio en la competitividad empresarial, Revista GTH, 1(1), 53-62.

Ramírez, M. (2011). ¿Cómo se puede lograr que los emprendedores organizacionales conciban sus visiones desarrollando diferentes métodos investigativos? Revista Unisangil Empresarial, 4(1), 4-9.

Ramírez, M. (junio, 2012). Les visions conçus par les entrepreneurs dans le Business Model Social des maisons de retraités à Colombie: Le cas de Ruitoque Casa Mayor. Colloque «le Financement des entreprises et les stratégies de développement» «Management, Entrepreneuriat et Innovation", Sousse, Africa.

Revolon, F. (1999). L'acuité de la vision stratégique des dirigeants de PME: une étude exploratoire. Cahier de recherche, No.1999-09, Université de Nancy 2, GREFIGE.

Smida, A. (1992). Prospective des métamorphoses du système technique et management des ruptures technologiques (Thèse de Doctorat d'Etat ès Sciences de Gestion) Université de Caen Basse-Normandie.

Smida, A. (1995). Ingrédients de prospective et leviers de stratégie. En A. Noël, P. Véry, et M. Wissler, Perspectives en Management Stratégique, tome III (pp. 455-483), París: Economica.

Smida, A. (2006). Croisements de quelques fondements théoriques de la stratégie et de la prospective. A la recherche d'une cohérence entre les futurs, les moyens et l'environnement de l'entreprise. 5ème Colloque International de l'Association Tunisienne des Sciences de Gestion, Hammamet, Tunisie.

Smida, A. (2007). SMOCS, Un modèle de management anticipatif stratégique pour piloter l'organisation dans des environnements complexes. Gème Colloque International de l'Association Tunisienne des Sciences de Gestion, Hammamet, Tunisie.

Smida, A., \& Khelil, N. (2010). Repenser l'échec entrepreneurial des petites entreprises émergentes: proposition d'une typologie s'appuyant sur une approche intégrative. Revue Internationale P.M.E.: économie et gestion de la petite et moyenne entreprise, 23(2), 65-106.

Stabell, C. B., \& Fjeldstad, Ø. D. (1998). Configuring Value for Competitive Advantage: On Chains, Shops, and Networks. Strategic Management Journal, 19(5), 413-437.

Verstraete, T., \& Saporta B. (2006). Création d'Entreprise et Entrepreneuriat. Bordeaux. Université Montesquieu Bordeaux IV: Entrepreneuriat et Stratégie de l'IFREGE. Editions de l'ADREG. 
Warnier, V., Demil, B., \& Lecocq X. (2004). Le Business Model: l'oublié de la stratégie? 13ème Conférence Internationale de Management Stratégique - AIMS, Havre.

Wernerfelt, B. A. (1984). Resource-Based View of the Firm. Strategic Management Journal, 5(2), 171-180.

Yin, R.K. (1990), Case Study research: Design and Methods. Londres: Sage Publications.

Yin, R. K. (2003), Case Study Research: Design and Methods. California: Sage Publications.

Yunus, M., Moingeon B., \& Lehmann-Ortega L. (2010). Building Social Business Models: Lessons from the Grameen Experience. Long Range Planning, 43(2-3), 308-325. 